\title{
A REVIEW ON DISASTER WASTE MANAGEMENT
}

\author{
MANAS RANJAN DAS \& ADITYA DASH
}

Department Of Management, Siksha 'O' Anusandhan (Deemed To Be University), Bhubaneswar, Odisha

\begin{abstract}
Disasters may generate vast quantities of debris and waste due to their design and magnitude. Waste amounts from a single incident will be the sum of the entire community's average amount of waste production several times over. Such amounts will overload the current infrastructure and resources for handling solid waste. Disaster waste mismanagement may impact both the response and the long-term rehabilitation of a region impacted by the disaster. Disasters may generate vast quantities of debris and waste due to their design and magnitude. The waste will overload existing solid waste collection systems and affect other emergency response operations and recovery. The waste may have major environmental and public health implications if improperly handled, which may impair the overall recycling cycle. Past "disaster waste management" work has been either context-specific or case-specific, rendering the transition of lessons from one hazard incident to another impossible. This work is aimed at creating a framework knowledge of disaster waste management and in effect providing meaning- and crisis-transferable decision-making guidelines for emergency and waste managers.

KEYWORDS: Disaster Waste Management, Economic Rebuilding, Emergency Management, Healthcare Impacts, Management Principles, Rebuilding Process
\end{abstract}

Received: Jun 08, 2020; Accepted: Jun 28, 2020; Published: Aug 27, 2020; Paper Id.: IJMPERDJUN2020911

\section{INTRODUCTION}

Disasters may generate vast quantities of debris and waste due to their design and magnitude. Debris amounts may be the inverse of the impacted community's average rate of waste production several times over. Such amounts will overload the current infrastructure and resources for handling solid waste. The existence of catastrophe waste impacts nearly any part of an emergency response, including: inhibiting search and rescue operations and access to the impacted areas for emergencies and healthcare, and possibly presenting a public health danger. Bad management of a clean-up will contribute to sluggish and expensive recovery in the longer term[1].

Restricted reconstruction / repair may be carried out until the waste is extracted, sustained access to the waste is often potentially dangerous for public and environmental safety, and the persistence of waste can hinder psycho-social recovery. When properly handled, debris can become a vital tool in the cycle of clean-up and reconstruction, which can have a significant influence on social and economic development. Previous disaster waste management work was either context-specific or incident-specific and rendered it impossible to move lessons from one disaster case to another. The basic aims of this work were, therefore:1. to build a rigorous system for the study of disaster waste management science. 2. To grasp the complexities of high-level catastrophe waste management services program. 3. Investigating alternative decision-making methods for management of catastrophe wastes. 4. To recognize the need for potential studies[1]. 
A technique for multi-hazard, multi-context, integrated, innovative research was introduced. A cross case study was conducted using the model seen in the chart on the page below in Figure 1.

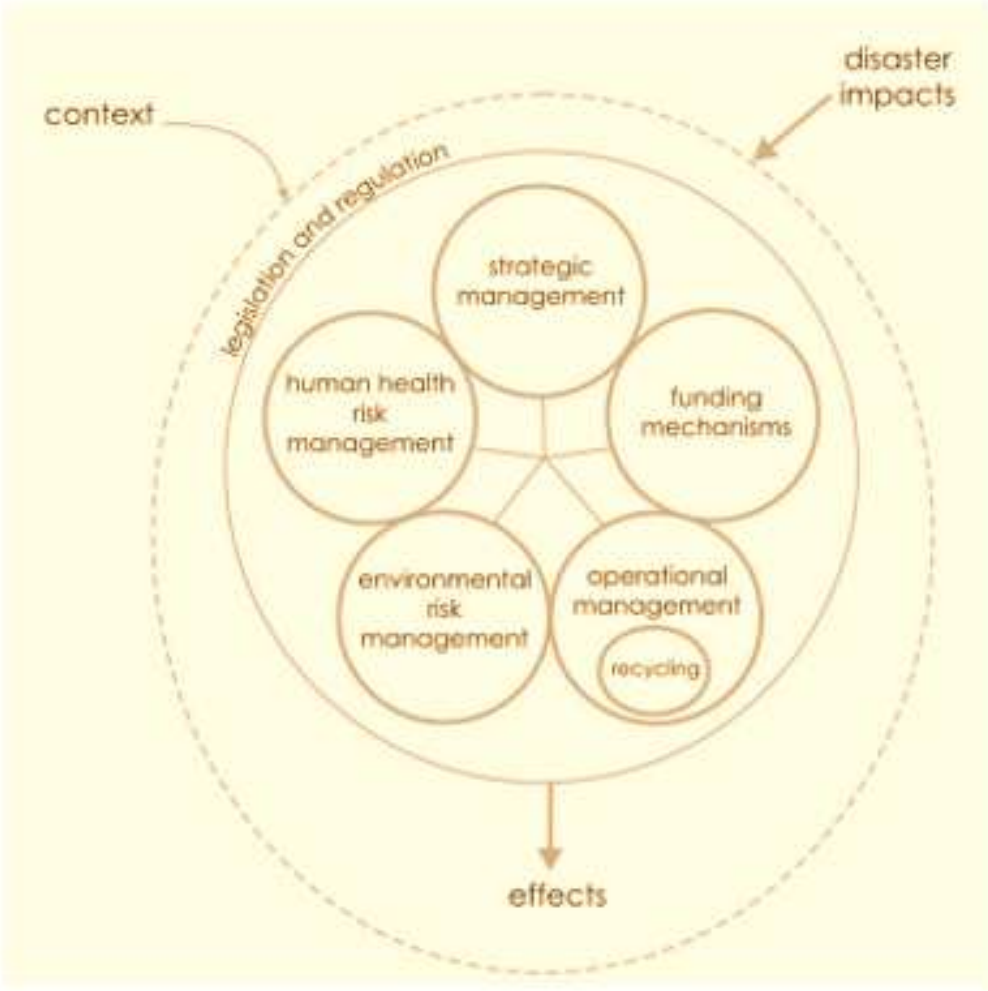

Fig.1: Cross-Case Study Analysis Model

\section{Impacts of Disasters}

Five disaster effect metrics have been suggested for the purposes of this study to characterize the effects of disaster (relevant to disaster waste management): disaster size, amount of affected people, regional range, and length of danger and degradation of road network. However, five main characteristics of the catastrophe waste were developed: amount of waste, danger to human safety, threat to environmental health, movement of waste and difficulty in managing waste. During the study research, the metrics are used qualitatively; furthermore, a semi-quantitative assessment method is recommended, so that the measures can be included in pre- and post-event preparation and research[2].

\section{Effects of Disasters}

To allow a qualitative evaluation of the effectiveness of a disaster waste management program for cross-case review, 12 criteria have been developed (see table 1). As for the impacts of the accidents, a semi-quantitative evaluation methodology has been proposed for potential usage in pre- and post-disaster scenarios. 
Table 1: Criteria for an Effective Disaster Waste Management System

\begin{tabular}{|c|l|}
\hline Environmental & $\begin{array}{l}\text { Adverse environmental effects are minimised. } \\
\text { Enwironmentally beneficial strategies encouraged (e.g. recycling). }\end{array}$ \\
\hline Economic & Operational (waste handling and disposal) costs are minimised. \\
Direct costs & Regulatory and strategic management costs are minimised. \\
Indirect costs & Local economy stimulated. \\
& $\begin{array}{l}\text { Potential future costs from enwironmental remediation and adverse } \\
\text { health effects are minimised }\end{array}$ \\
\hline Social & Improwes community spirit. \\
Psychosocial & Affected persons are empowered to participate in their own recovery. \\
Human health & Public understands and accepts disaster waste management strategy. \\
& $\begin{array}{l}\text { Human health both general public and workers, acute and chronic) } \\
\text { risks are effectively managed }\end{array}$ \\
\hline Recovery & $\begin{array}{l}\text { The recowery is timely. } \\
\text { The recovery facilitates equitable outcomes across the community. }\end{array}$ \\
\hline
\end{tabular}

\section{Strategic Management}

A strategic management system, distinct from the functions and operational frameworks of peacetime (or business as usual) is required for large-scale events. In addition, as the scale of the disaster rises, the handling of catastrophe waste at higher rates of government will be systematic. The recovery agency will also be in charge of resource implementation with good support from peacetime waste / environmental authority.

There are actually a broad variety of emergency waste reduction funding strategies open. Nevertheless, public financing was primarily used in reaction to the traumatic incidents examined in this study, except in situations where relief from disasters is usually privately financed. There was also a movement towards explicitly assisted activities in case studies, rather than payment by lump sum or repayment. Given the high potential for negative consequences from inadequate management of disaster waste, the author proposes that disaster waste management (especially detritus removal and demolition) must be publicly financed and encouraged directly[2].

Diverse organizational control approaches were present throughout the case studies. It has been observed commonly that detritus collection operations and debris disposal in significant repair work can be encouraged individually. At the other side, the selection, removal and recycling of waste is better performed individually to mitigate the cumulative costs of a badly executed clean-up. Ideally structured recycling systems would provide waste treatment procedures "cradle to severe": that is, waste processing facilities should be related to destruction and waste disposal[3].

\section{Recycling}

Many post-disaster recycling hurdles have been identified: time constraints; reduced supply of resources; mixed complexity of waste; hazards in the waste matrix; relocated populations; post-disaster demand problems (capacity, affordability, disturbance, space limitations); contracting arrangements; quality and viability of alternate waste management solutions.

In general, recycling can be performed offsite where recycling is needed and there is an immediate need to clear the contaminated region (unless there are adequate waste management facilities). For this the possible increased expenses will be known as indirect cost savings[4]. 


\section{Healthcare Impacts and Management}

Post-disaster future environmental and public safety threats would no doubt escalate due to the pace and amount of research being carried out. The enhanced complexity and constraints of regulatory and organizational resource resources must be taken into consideration when implementing effective risk reduction strategies. The analyst observed that simplified site-specific approval procedures that identify and protect against increasing threats are typically a more desirable solution than offering waivers for permits.

Disasters may generate vast quantities of debris and waste due to their design and magnitude. Researchers estimated in a study of previous disasters in the United States (US) that in certain instances debris amounts from a single incident is the equivalent of five to fifteen times the entire community's total waste generation average. Scientists also noticed identical percentages after the earthquake at the Indian Ocean. Such amounts exceed current infrastructure and resources for solid waste disposal. Figure 2 displays the large amounts of waste a month after the Indian Ocean Tsunami on Phi Phi Island[5].

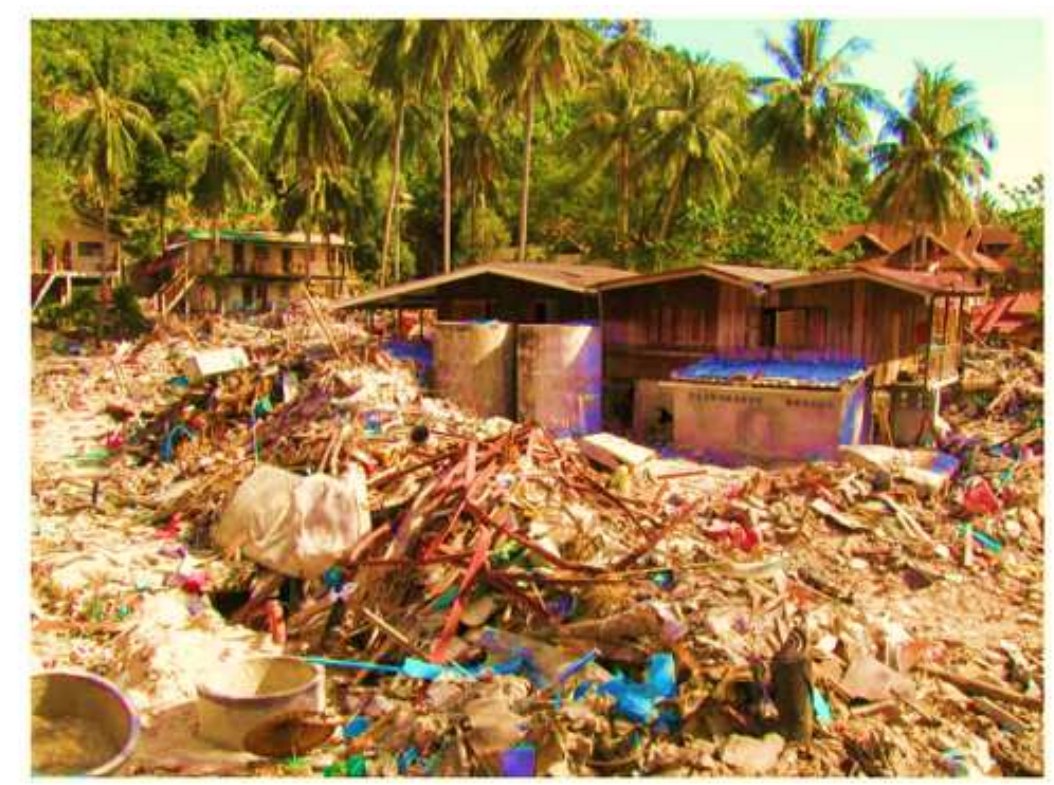

Fig. 2: Phi Phi Island, Thailand, one month after the Indian Ocean T sunami (photo source Erica Seville).

\section{LITERATURE REVIEW}

Disaster waste impacts just about any part of a disaster response and recovery operation. Disaster debris may create roadblockages in the immediate response. Following the Great Hanshin-Awaji earthquake in Japan, road blockages blocked building entry, which in turn hindered survivors from contacting rescuers, emergency responders and lifeline assistance. The existence of pollution inside a group often presents a possible danger to public safety. Organic wastes and standing water pools (potentially induced by debris blocking flow paths) can become breeding grounds for the vectors.Vector transmitted diseases are a widespread type of communicable disease encountered during a disaster, particularly where there are large numbers of displaced persons. The probability of outbreaks is therefore fairly small[6]. 
Bad management of a clean-up will contribute to sluggish and expensive recovery in the longer term. First, waste management is on the vital recuperation route. Restricted restoration and repair should be done before disposal of the waste. In Haiti, about two years after the earthquake, an estimated half of the 9 million cubic meters of debris remained to be removed. As studies in Sri Lanka have established after the Indian Ocean tsunami, sustained exposure to the waste is also highly hazardous for public and environmental safety. If successfully handled, debris can become a vital tool in the clean-up and restoration process, which can have a beneficial impact on social which economic recovery[7].

Historically, the management of waste from disasters was handled as a logistic exercise. The primary emphasis was to extract the waste from the contaminated region with no regard for the long lasting environmental impacts. The town was heavily affected by a massive earthquake at L'Aquila. The rubble has been collected in a field behind the Basilica, now comprising the Botanical Gardens. To stabilize the improperly compacted fill, this site needed continuing remediation. Since World War II, 14 million cubic meters of debris from destroyed houses were stacked up on top of an elevated hill in Stuttgart, Germany. This slope, now named Birkenkopf, is a war memorial[8].

Following the earthquake of 1931, the waste disposal approach in Napier, New Zealand was to drain the unsorted rubble first into a lagoon (Figure 3) and subsequently to the neighbouring town shore. The above disposal site gradually grew into a 30-40 m large domain which now runs the length of Napier's commercial section. With rising understanding and concern regarding the possible health, social and economic effects of waste management approaches, as well as the growing scale and magnitude of disasters, contemporary catastrophe waste managers need to adopt a much more comprehensive and thoughtful strategy[9].

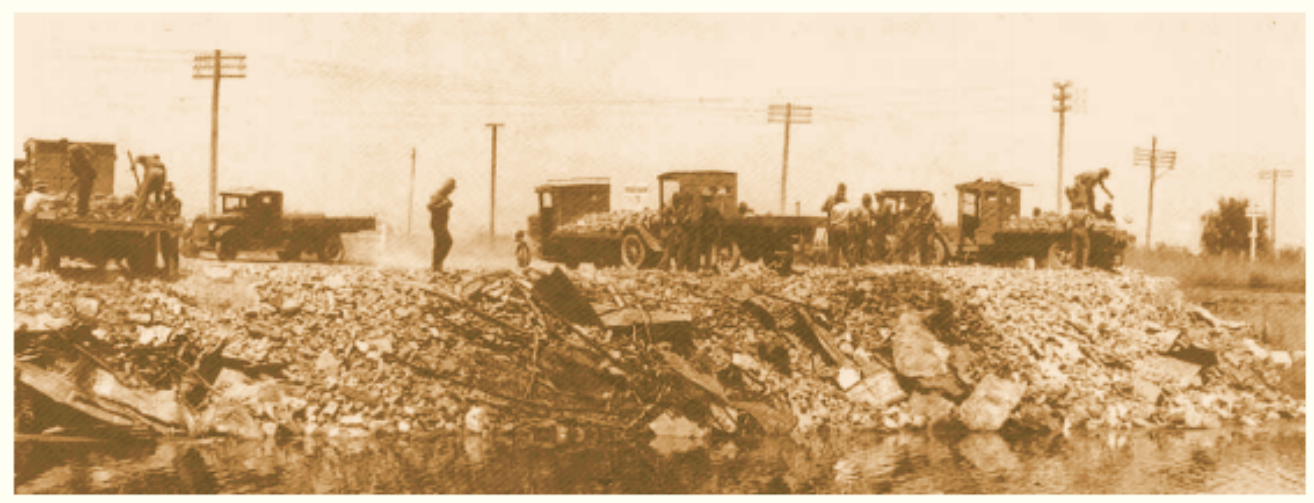

Fig. 3: Following the 1931 Napier earthquake, rubble from collap sed buildings was first dumped into a lagoon just west of the Napier CBD (pictured) and later along the Napier waterfront (photo source Alexander Turnbull Library)

Improved expectations for public facilities are rising possible disaster impacts in many areas. However, intensified urbanization and reliance on complicated networks of services raises the susceptibility of a population to a disaster[10].

\section{CONCLUSIONS}

The understanding of disaster waste management is still significantly gaping. Current literature primarily focuses on technological dimensions of catastrophe waste management and neglects the structural (organizational, legal and financial) structures. The knowledge of the impacts of disaster waste management systems is still minimal, including the social and 
economic impacts.

A literature review is envisaged to shape a basis for potential systematic and coherent catastrophe waste management studies. Work would in effect contribute to improved readiness and response to emergency management problems.

It is anticipated that the ideas in this document, especially the implementation of a disaster management preparation strategy focused on key decisions, would enable decision-makers to handle catastrophe risk effectively in the future. Knowing the primary decisions to be taken, the major decision-makers and their relationships can offer decisionmakers more trust in making prompt and successful decisions in a number of crisis scenarios

\section{REFERENCES}

1. K. Onan, F. Ülengin, and B. Sennarołlu, "An evolutionary multi-objective optimization approach to disaster waste management: A case study of Istanbul, Turkey," Expert Syst. Appl., 2015.

2. M. Asari et al., "Strategy for separation and treatment of disaster waste: A manual for earthquake and tsunami disaster waste management in Japan," J. Mater. Cycles Waste Manag., 2013.

3. Á. Lorca, M. Çelik, Ö. Ergun, and P. Keskinocak, "A Decision-support Tool for Post-disaster Debris Operations," in Procedia Engineering, 2015.

4. T. Tabata, Y. Wakabayashi, P. Tsai, and T. Saeki, "Environmental and economic evaluation of pre-disaster plans for disaster waste management: Case study of Minami-Ise, Japan,” Waste Manag., 2017.

5. J. Crowley, "A measurement of the effectiveness and efficiency of pre-disaster debris management plans," Waste Manag., 2017.

6. C. Brown, M. Milke, and E. Seville, "Disaster waste management: A review article," Waste Management. 2011.

7. E. M. A. Zawawi, N. S. Yusof, and Z. Ismail, "Adoption of post-disaster waste management plan into disaster management guidelines for Malaysia," J. Mater. Cycles Waste Manag., 2018.

8. C. Brown and M. Milke, "Recycling disaster waste: Feasibility, method and effectiveness," Resour. Conserv. Recycl., 2016.

9. B. P. Antillator, M. Bjerregaard, and L. Jonsson, "Disaster Waste Management Guidelines," 2011.

10. N. S. Yusof, E. M. A. Zawawi, and Z. Ismail, "Disaster Waste Management in Malaysia: Significant Issues, Policies \& Strategies," in MATEC Web of Conferences, 2016. 